\title{
The relation between indoor environnemental quality (IEQ) and energy consumption in building based on occupant behavior - A review
}

\author{
Iman Asadi ${ }^{1}$ a , Norhayati Mahyuddin ${ }^{1}$ and Payam Shafigh ${ }^{1}$ \\ ${ }^{1}$ Department of Building Surveying, Faculty of Built Environment, University of Malaya, 50603 Kuala Lumpur, MALAYSIA
}

\begin{abstract}
Indoor Environmental Quality (IEQ) is an important topic which impacts on occupant health, productivity and also energy consumption in buildings. The four main parameters for IEQ evaluation are: Thermal comfort, indoor air quality, visual comfort and aural comfort. The occupant behavior in buildings defines as any direct or indirect act which an occupant selects to change the displeasure environmental condition into the comfort conditions. The selected behavior by human has a significant impact on the energy consumption in buildings. This paper reviews the methods which used to simulate IEQ parameters, energy consumption and human behavior in buildings. It aims to promote the idea of more consideration about the relation between occupant behavior and energy usage in buildings. This summary of existing studies about the importance of human behavior factor in energy simulation software helps to identify new methods and strategies for simulating IEQ, Energy and behavior.
\end{abstract}

Keywords: indoor environmental quality (IEQ), energy consumption, human behavior

\section{Introduction}

These Most people spend more than $90 \%$ of their time indoors [1]. The importance of Indoor environmental quality (IEQ) is it impacts on energy efficiency and also productivity and health of occupants. Thermal comfort, indoor air quality, visual comfort and aural comfort are four main physical parameters which are normally used to determine IEQ. There will be a rising focus on energy consumption and indoor environmental quality in existing buildings and the future buildings. There is a significant relation between energy consumption and the features which are considered in the indoor environment (temperature, ventilation and lighting) and building design and operation. According to the recent studies the cost of poor indoor environment for the employer, the owner and also for the society, as a whole are frequently considerably higher than the cost of the energy which are used in the same building [2] .

The "behavior" refers to any direct or indirect action that a building occupant selects to manage their surrounding environment. Human behavior is maybe the most important IEQ study topic because human activities and decisions deeply influence every IEQ determinant at every stage of building's lifecycle. Through understanding human behavior the energy prediction models will be improved .The problem is measurement and quantification the human behavior and translation that into the energy algorithm. The technology of

\footnotetext{
a asadi8564@gmail.com
}

simulation is based on several disciplines like as computer and numerical science, physics, mathematic and so on. For simulating human behavior in building, social science modeling can be a useful method.

The aim of this paper is to review the relation between IEQ and energy consumption in building based on Occupant behavior. Also, the human and energy simulation methods are considered.To achieve the objective of this paper, the related studies to the IEQ and building energy usage based on human behaviour are identified through internet searches, review of published papers and conversation with other researcher.The results and methods of these researches areconsidered and the simualated software and methods are analysed.

\section{Indoor environmental quality (IEQ)}

Based on United States Green Building Council (USGBC), Water efficiency, materials and resources, energy and atmosphere, sustainable sites and indoor environmental quality should be consider for a green building. Measuring of IEQ is commonly validate by four aspects: i.e. Thermal comfort (TC), Indoor air quality (IAQ), Aural comfort (AC) and Visual comfort (VC) [3, 4].

\subsection{Thermal comfort}


Thermal comfort is defined "that condition of mind which expresses satisfaction with the thermal environment" according ISO 7730 standard definition and also ASHRAE Standard 55, states that, success means that a building meets the needs of $80 \%$ of the occupants $[5,6]$. Air temperature $\left({ }^{\circ} \mathrm{C}\right)$, mean radiant temperature $\left({ }^{\circ} \mathrm{C}\right)$, air velocity $(\mathrm{m} / \mathrm{s})$ and relative humidity (\%) are the four environmental parameters which influence thermal perception of occupants while, metabolic rate (Met) and clothing value (Clo) are considered as personal parameters [7] .Air temperature, air velocity and relative humidity are measured directly. Equation for calculating mean radiant temperature is:

$$
T_{m r t}=\left(\Sigma F_{s i} T_{i}^{4}\right)^{1 / 4}
$$

Where $\mathrm{T}_{\mathrm{i}}=$ Temperature of black surface, $\mathrm{F}_{\mathrm{si}}=$ fraction of radiation of the black sphere which reaches the $i^{\text {th }}$

Each person has a special metabolism rate. These rates are able to change according to the activities done, or under special environmental situations. The movement of air and relative humidity can reduce the insulating ability of the cloth depending on the sort of cloth [8]. Based on mentioned parameters the Predicted mean vote (PMV) and predicted percent of dissatisfied (PPD) indexes are defined.

\subsection{Indoor air quality}

The Indoor air quality (IAQ) is related to the health and comfort of occupants and poor IAQ is related to the Sick Building Syndrome (SBS). The change amount of pollutant per volume of air over time is expressed by:

$V d C_{i} / d t=P_{i}-($ ventilation $)-($ exfiltration $)-($ sorption, decay, cleaning) $[\mu \mathrm{g} / \mathrm{s}]$

Where: $\mathrm{V}=$ volume of space $\left(\mathrm{m}^{3}\right), \mathrm{C}_{\mathrm{i}}=$ concentration of pollutant in indoor air $\left(\mu \mathrm{g} / \mathrm{m}^{3}\right)$

There are different group of chemical and biological pollutants in indoor air. There are different research which considered $\mathrm{CO}_{2}$ concentration as an IAQ Index [911]. The equation to calculate ventilation rate for considering IAQ based on $\mathrm{CO}_{2}$ concentration is:

$$
V_{\text {rate }}=\frac{\text { EX rate }}{\mathrm{CO} 2 \text { in }- \text { CO2out }} \text {, }
$$

Where $\mathrm{V}$ rate = effective ventilation rate in $\mathrm{cfm}$ of Outdoor Air (OA) per person ,EX rate = average exhalation rate of $\mathrm{CO} 2$ per person in the measured area, $\mathrm{CO} 2$ in $=$ measured inside concentration level of carbon dioxide, $\mathrm{CO} 2$ out $=$ outside carbon dioxide concentration, measured or estimated.

\subsection{Aural comfort}

The direct and diffuse indoor sound pressure which is perceived depends on characteristics of the space like as volume of space. In the field of diffuse the sound pressure level perceived is:

$$
L_{p} \cong L_{w}+10 \log (4 / A)[d B]
$$

Where $\mathrm{L}_{\mathrm{p}}=$ sound pressure level, $\mathrm{L}_{\mathrm{w}}=$ sound pressure level in point, $\mathrm{A}=$ surface area of the enclosed space .

The sources of noise (when sound disturb the occupant) are indoor sources like as HVAC systems, sanitary, drinking water, flank transmission through the pipe systems into the building structure installations and outdoor sources like as traffic jam.

\subsection{Visual comfort}

Lighting (counting as luminance, difference between clarify surfaces, and the spectrum of light) can influence residents' health and efficiency both in a straight line, since work efficiency depends on vision, and not directly, because lighting can straight attention, or affect motivation[12]. The daylight and artificial light are two main sources of light. Based on following equation the amount of direct lighting level is [13]:

$$
E=n \Phi \eta /(l \times b)
$$

Where: $\mathrm{n}=$ number of light sources; $\Phi=$ light flux of all light sources (lumen); $\eta=$ output (efficiency) of light source; $1=$ length of space $(\mathrm{m}) ; \mathrm{b}=$ width of space $(\mathrm{m})$.

\subsection{Overall IEQ acceptance}

However, each IEQ parameter has an important effect on occupant comfort and productivity, perceive of overall IEQ acceptance is more complicated. There are several studies which assess the IEQ acceptance among occupant by using a multivariate logistic regression $[4,9,10]$.The demonstrated model is:

$$
\dot{\varnothing}_{0}=1-\frac{1}{1+\exp \left(C_{0,0}+\sum_{i=1}^{4} C_{i, 0} \oint_{i}\left(\zeta_{i}\right)\right)}
$$

Where: $\mathscr{\varnothing}_{0}=$ the overall IEQ acceptance, $\mathrm{C}_{0,0}$ and $\mathrm{C}_{\mathrm{i}, 0}$ are the regression constants, $\mathscr{\varnothing}_{\mathrm{i}}$ is the occupant acceptance related to the thermal sensation vote $\zeta_{1}$, the $\mathrm{CO}_{2}$ concentration $\zeta_{2}(\mathrm{ppm})$, the illumination level $\zeta_{3}(\mathrm{~lx})$ and the sound pressure level $\zeta_{4}(\mathrm{dBA})$.

The thermal environment acceptance $\wp_{1}\left(\zeta_{1}\right)$, is :

$$
\dot{\emptyset}_{1}=0.95 \exp \left[-\left(C_{0, a} \zeta_{1}^{2}+C_{1,1} \zeta_{1}^{4}\right)\right]
$$

And the acceptance of $\dot{\varnothing}_{2}\left(\zeta_{2}\right), \varnothing_{3}\left(\zeta_{3}\right)$ and $\dot{\emptyset}_{4}\left(\zeta_{4}\right)$ are demonstrated by below regression when $C_{0, j}$ and $C_{1, j}$ are regression coefficient : 


$$
\dot{ø}_{j}=1-\frac{1}{1+\exp \left(C_{0, j}+C_{1, j} \zeta_{j}\right.}, j=2, \ldots, 4
$$

\section{Human behavior \& building energy consumption}

The amount of energy consumption in residential and commercial buildings was about $41 \%$ of total energy usage in U.S in 2014. As illustrated in Figure 1, according to Hoes et al.[14], Energy use in buildings is closely linked to the behavior of occupants in building. The researches on thermal comfort and adaptive control [15], lighting control [16], possible window control [17] , and shading control [16] are some of the research subjects which began to assess the occupant behavior that influences in building operation and energy efficiency.

Behavioral in buildings are intricately linked with multiple factors that stem from the physical, cultural, psychological, social, and so on [18]. Some studies have also suggested that the perceived ability or inability to behave adaptively in the field has a psychological effect that must be considered by thermal comfort calculations $[15,19,20]$

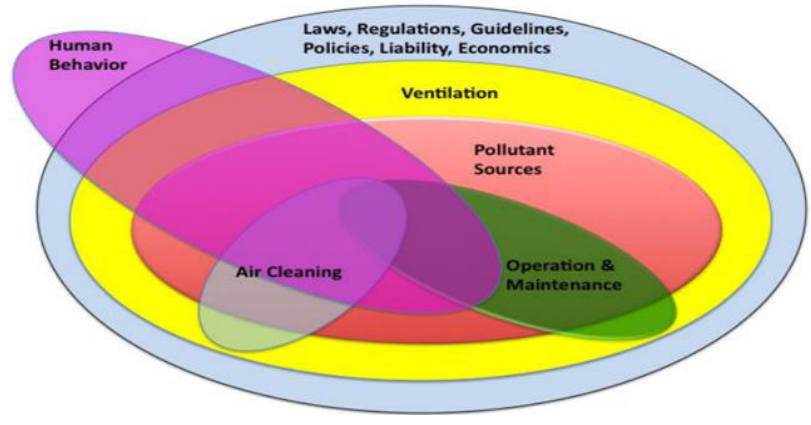

Figure 1. Inter relationships of IEQ determinants. Human Behavior factors affect all other determinants (Source:T.J. Phillips).

\subsection{IEQ simulation tools}

The aim of this part is to consider simulation tools and software which are using to predict occupant satisfaction, energy efficiency and occupant comfort in buildings. The simulation of building is a good strategy for testing building efficiency in different conditions[21] .

Estimating the amount of energy consumption and designing the HVAC system is the most common usage of simulations. In some studies IEQ aspects are considered based on temperature set points and ventilation rate[22].There are different developed computational models for simulating each IEQ aspect $[21,23,24]$. Most of these simulating models consider each IEQ aspect separately and the inability to consider the interaction of a specific IEQ parameter with other IEQ Parameter is the drawback of these methods[25].Based on U.S Department of Energy (DOE2015), just 2 of the 417 simulation software in the Building Energy, are capable to simulate all four IEQ aspects. Loonen et al. reviewed different building performance simulation (BPS) programs and their capability to calculate the various IEQ parameters. This overview is shown in Fig 2.
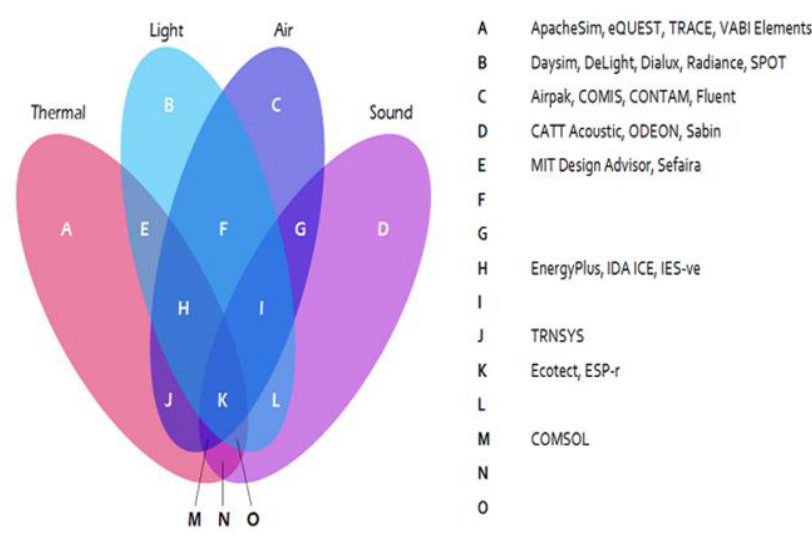

Figure2. overview of different BPS programs [22].

\subsection{Human behavior}

The "behavior" is the actions or reactions of an object, usually in relation to its environment. In the most research, the presence of occupant and heat generation and energy consumption by occupant are considered without taking account the way which they behave to use energy [26]. Considering the actual behavior of occupant in simulation methods leads to more realistic simulation. Recognition information within humans are captured by many behavior illustration models[27] .

The human behavior representation model based on earlier studies are summarized in Table 1.Based on Langevin suggestion [28], there are different steps to acheive better understand about the concept of human behavior simulation. These suggested steps are:
a) Additional longitudinal field study
b) Individually behavior modeling
c) Assessment of behaviors and their sequencing
d) Behavior modeling in multiple building types
e) An accessible behavior/energy co-simulation structure

Table 1.Summary of human behavior representation model

\begin{tabular}{|c|c|c|}
\hline Study & Proposed model & Description \\
\hline [27] & $\begin{array}{c}\text { ACT (atomic } \\
\text { components of } \\
\text { thoughts) }\end{array}$ & $\begin{array}{c}\text { focuses on the way which } \\
\text { humans organize their } \\
\text { knowledge in order to } \\
\text { behave intelligently }\end{array}$ \\
\hline$[29]$ & $\begin{array}{c}\text { CAPS (concurrent } \\
\text { activation based } \\
\text { production system) }\end{array}$ & $\begin{array}{c}\text { Considering each specifying } \\
\text { the conditions and consequent } \\
\text { actions }\end{array}$ \\
\hline
\end{tabular}




\begin{tabular}{|c|c|c|}
\hline$[30]$ & $\begin{array}{c}\text { COGNET } \\
\text { (cognition as a } \\
\text { network of tasks) }\end{array}$ & $\begin{array}{c}\text { Consider cognitive behavior by } \\
\text { assumption of human } \\
\text { capability to perform multi } \\
\text { tasks }\end{array}$ \\
\hline [31] & $\begin{array}{l}\text { CCT (cognitive } \\
\text { complexity theory) }\end{array}$ & $\begin{array}{l}\text { models human performance } \\
\text { as Goals, Operators, Methods } \\
\text { and Selection rules }\end{array}$ \\
\hline [32] & $\begin{array}{l}\text { DCOG (Distributed } \\
\text { cognition) }\end{array}$ & $\begin{array}{l}\text { explain that cognition is } \\
\text { distributed through the } \\
\text { environment }\end{array}$ \\
\hline [33] & $\begin{array}{l}\text { EPIC (executive } \\
\text { process/interactive } \\
\text { control) }\end{array}$ & $\begin{array}{c}\text { Focus on the perceptual and } \\
\text { intellectual. }\end{array}$ \\
\hline [34] & $\begin{array}{l}\text { APEX (architecture } \\
\text { for procedure } \\
\text { execution) }\end{array}$ & $\begin{array}{c}\text { Consider human behavior in } \\
\text { dynamic environment }\end{array}$ \\
\hline [35] & $\begin{array}{l}\text { Brahms (Business } \\
\text { redesign agent- } \\
\text { based holistic } \\
\text { modeling system) }\end{array}$ & $\begin{array}{l}\text { Considering human social } \\
\text { behavior over times }\end{array}$ \\
\hline [36] & $\begin{array}{l}\text { HOS (human } \\
\text { operator simulator) }\end{array}$ & $\begin{array}{l}\text { a model of human abilities } \\
\text { and restrictions to support } \\
\text { the design of human-machine } \\
\text { systems }\end{array}$ \\
\hline
\end{tabular}

\section{Discussions}

Thermal comfort, Indoor air quality, aural comfort and visual comfort are the four main parameter to evaluate the IEQ in buildings. The poor IEQ is caused sick building syndrome, less human productivity and also more energy consumption. One the most important reason for considering IEQ in buildings is reducing the amount of energy usage.However, the heating, cooling, ventilation, water heating, lighting and electronics equipment are the main reasons for increasing building energy consumption, but the occupant activities affect on all of them.Occupant behavior is a physical and also psychological response to the environmental conditions to manage the dissatisfied conditions. This is why, the human behaviour is closely related to the energy usage in residential and commercial buildings and should be consider as an important factor in the field of built environment.

\section{Conclusions}

Based on review different paper in the field of IEQ it is concluded that, most researches were considered the relation between just one or two IEQ parameters and occupant satisfaction. Some researcher promoted a multivariate logistic regression to predict the overall IEQ acceptance based on subjective and objective measurement.These studies focused on occupant satisfaction and the lack of a relationship between overall IEQ parameter and energy consumption is obvious. Other studies used different type of simulation methods and softwares to predict the amount of energy consumption by considering one or two IEQ parameters. The disability of simulating all IEQ factors at the same time and considering the affect of human behavior is the drawback of these methods.Also, some study promoted different models to simulate the human behavior. In a simulation process, considering physical, psychological and social behavior of occupant is required. Since the human behavior changes the energy usage in building, the aim of this consideration is to measure and predict the occupant behavior while facing with uncomfortable conditions. The complexity and uncertainties of occupant behavior leads to lack of behavior prediction and feedback in simulating software. The current simulation programs have a limitation to predict dynamic behavior of occupant and just supported implausible forms of human behavior.

Therefore, the development of existing knowledge to be used in considering and simulating human behavior in various methods and different kind of buildings with different IEQ conditions provide a valuable contribution in the energy simulation programs. Also, it is suggested to use an algorithm to consider building energy consumption based on human behavior by considering all IEQ factors

\section{References}

1. De Giuli, V., O. Da Pos, and M. De Carli, Indoor environmental quality and pupil perception in Italian primary schools. Building and Environment, 2012. 56: p. 335-345.

2. Olesen, B.W., Revision of EN 15251: indoor environmental criteria. REHVA European HVAC Journal, 2012. 49(4): p. 6-12.

3. Clausen, G. and D.P. Wyon, The combined effects of many different indoor environmental factors on acceptability and office work performance. HVAC\&R Research, 2008. 14(1): p. 103-113.

4. Lai, A., et al., An evaluation model for indoor environmental quality (IEQ) acceptance in residential buildings. Energy and Buildings, 2009. 41(9): p. 930-936.

5. Standard, A., 55: Thermal Environmental Conditions for Human Occupancy American Society of Heating. Refrigeration and Air Conditioning Engineers, Atlanta, USA, 1992.

6. ISO, C., Ergonomics of the thermal environment-Analytical determination and interpretation of thermal comfort using 
calculation of the PMV and PPD indices and local thermal comfort criteria. 2005, Brussels. European committee for standardization.

7. Asadi, I., I. Hussein, and K. Palanisamy. Analysis on Thermal Comfort of AirConditioned Buildings in Malaysia: Case Study of Universiti Tenaga Nasional. in Applied Mechanics and Materials. 2014. Trans Tech Publ.

8. Havenith, G., Heat balance when wearing protective clothing. Annals of Occupational Hygiene, 1999. 43(5): p. 289-296.

9. Cao, B., et al., Development of a multivariate regression model for overall satisfaction in public buildings based on field studies in Beijing and Shanghai. Building and Environment, 2012. 47: p. 394-399.

10. Wong, L., K. Mui, and P. Hui, A multivariatelogistic model for acceptance of indoor environmental quality (IEQ) in offices. Building and Environment, 2008. 43(1): p. 1-6.

11. Asadi, I. and I. Hussein, Indoor Air Quality (IAQ) Acceptance in Universiti Tenaga National.

12. Hygge, S. and I. Knez, Effects of noise, heat and indoor lighting on cognitive performance and self-reported affect. Journal of Environmental Psychology, 2001. 21(3): p. 291-299.

13. Visser, R., Verlichting en interieur. 1992: Dekker/vd Bos \& Partners.

14. Hoes, P., et al., User behavior in whole building simulation. Energy and buildings, 2009. 41(3): p. 295-302.

15. Brager, G.S. and R.J. de Dear, Thermal adaptation in the built environment: a literature review. Energy and buildings, 1998. 27(1): p. 83-96.

16. Bourgeois, D., C. Reinhart, and I. Macdonald, Adding advanced behavioural models in whole building energy simulation: a study on the total energy impact of manual and automated lighting control. Energy and Buildings, 2006. 38(7): p. 814-823.

17. Rijal, H.B., et al., Using results from field surveys to predict the effect of open windows on thermal comfort and energy use in buildings. Energy and Buildings, 2007. 39(7): p. 823-836.

18. Lee, Y.S., Y.K. Yi, and A. Malkawi. Simulating human behaviour and its impact on energy uses. in 12th Conference of International Building Performance Simulation Association, Sydney Austrialia. 2011.

19. Leaman, A. and B. Bordass, Are users more tolerant of 'green'buildings? Building Research \& Information, 2007. 35(6): p. 662-673.

20. Simonson, C., M. Salonvaara, and T. Ojanen, The effect of structures on indoor humiditypossibility to improve comfort and perceived air quality. Indoor Air, 2002. 12(4): p. 243-251.

21. Hensen, J. and R. Lamberts, Introduction to building performance simulation. Building performance simulation for design and operation, 2011: p. 1-14.

22. Loonen, R., M. Loomans, and J.L. Hensen, Towards predicting the satisfaction with indoor environmental quality in building performance simulation. 2015.

23. Zhang, Z. and Q. Chen, Prediction of particle deposition onto indoor surfaces by CFD with a modified Lagrangian method. Atmospheric Environment, 2009. 43(2): p. 319-328.

24. Vorländer, M., Computer simulations in room acoustics: Concepts and uncertaintiesa). The Journal of the Acoustical Society of America, 2013. 133(3): p. 1203-1213.

25. Citherlet, S., J. Clarke, and J. Hand, Integration in building physics simulation. Energy and Buildings, 2001. 33(5): p. 451-461.

26. Kashif, A., et al., Simulating the dynamics of occupant behaviour for power management in residential buildings. Energy and Buildings, 2013. 56: p. 85-93.

27. Anderson, J. and C. Lebiere, The atomic components of thought Lawrence Erlbaum. Mathway, NJ, 1998.

28. Langevin, J., Human Behavior \& Low Energy Architecture: Linking Environmental Adaptation, Personal Comfort, \& Energy Use in the Built Environment. 2014.

29. Just, M.A., P.A. Carpenter, and S. Varma, Computational modeling of high-level cognition and brain function. Human Brain Mapping, 1999. 8: p. 128-136.

30. Zachary, W., J.M. Ryder, and J.H. Hicinbothom, Cognitive task analysis and modeling of decision making in complex environments. Making decisions under stress: Implications for individual and team training, 1998: p. 315-344.

31. Card, S.K., A. Newell, and T.P. Moran, The psychology of human-computer interaction. 1983.

32. Eggleston, R.G., M.J. Young, and K.L. McCreight. Distributed cognition: A new type of human performance model. in Proceedings of the aiaa fall symposium series technical reports. North Falmouth, Massachusetts: American Institute of Aeronautics and Astronautics.(Cité page 41.). 2000.

33. Kieras, D.E. and D.E. Meyer. Predicting human performance in dual-task tracking and decision making with computational models using the EPIC architecture. in Proceedings of the First International Symposium on Command and Control Research and Technology, National Defense University, June. Washington, DC: National Defense University. 1995.

34. Freed, M.A., Simulating human performance in complex, dynamic environments. 1998 , Northwestern University.

35. Sierhuis, M., W.J. Clancey, and R.J. Van Hoof, Brahms: a multi-agent modelling environment for simulating work processes and practices. 
International Journal of Simulation and Process Modelling, 2007. 3(3): p. 134-152.

36. Wherry Jr, R.J., The human operator simulator-HOS, in Monitoring behavior and supervisory control. 1976, Springer. p. 283-293. 